\title{
Wave climate in the Arkona Basin, the Baltic Sea
}

\author{
T. Soomere ${ }^{1,2}$, R. Weisse ${ }^{3}$, and A. Behrens ${ }^{3}$ \\ ${ }^{1}$ Institute of Cybernetics at Tallinn University of Technology, Akadeemia tee 21, 12618 Tallinn, Estonia \\ ${ }^{2}$ Estonian Academy of Sciences, Kohtu 6, 10130 Tallinn, Estonia \\ ${ }^{3}$ Institute of Coastal Research, Helmholtz-Zentrum Geesthacht, Max-Planck-Strasse 1, Geesthacht, Germany \\ Correspondence to: T. Soomere (soomere@cs.ioc.ee)
}

Received: 22 October 2011 - Published in Ocean Sci. Discuss.: 21 November 2011

Revised: 5 April 2012 - Accepted: 5 April 2012 - Published: 17 April 2012

\begin{abstract}
The basic features of the wave climate in the Southwestern Baltic Sea (such as the average and typical wave conditions, frequency of occurrence of different wave parameters, variations in wave heights from weekly to decadal scales) are established based on waverider measurements at the Darss Sill in 1991-2010. The measured climate is compared with two numerical simulations with the WAM wave model driven by downscaled reanalysis of wind fields for 1958-2002 and by adjusted geostrophic winds for 1970-2007. The wave climate in this region is typical for semi-enclosed basins of the Baltic Sea. The maximum wave heights are about half of those in the Baltic Proper. The maximum recorded significant wave height $H_{\mathrm{S}}=4.46 \mathrm{~m}$ occurred on 3 November 1995. The wave height exhibits no long-term trend but reveals modest interannual (about $12 \%$ of the longterm mean of $0.76 \mathrm{~m}$ ) and substantial seasonal variation. The wave periods are mostly concentrated in a narrow range of 2.6-4 s. Their distribution is almost constant over decades. The role of remote swell is very small.
\end{abstract}

\section{Introduction}

Observations, measurements and modelling of wave fields in the Baltic Sea basin go back for many decades (Schmager et al., 2008; Weisse and von Storch, 2010). Wave observations from ships and simple fetch-based models have been extensively used for the compilation of older wave atlases (Rzheplinsky, 1965). Visual observations from several coastal hydrometeorological stations of the former USSR have been performed since the 1950s (Soomere and Räämet, 2011b). Instrumental wave measurements were probably first launched at the end of the 1970s in Swedish coastal waters (Broman et al., 2006). They have been performed systematically from the 1980s in the northern Baltic Proper and in sea areas surrounding Finland (Kahma et al., 2003), and from the 1990s in the southern and Southwestern (SW) Baltic Sea (Pettersson et al., 2010). These studies have been complemented by several numerical reconstructions of the wave climate (Jönsson et al., 2003; Augustin, 2005; Schmager et al., 2008; Räämet et al., 2010; Räämet and Soomere, 2010; Tuomi et al., 2011).

The input of wave studies into the climatology of the northern Baltic Proper is extensively documented (Kahma et al., 2003; Broman et al., 2006; Soomere, 2008; Soomere and Räämet, 2011b). A comparison of the instrumentally measured and visually observed wave parameters with the results of numerical simulations has revealed interesting spatial patterns of the Baltic Sea wave heights and approach directions and their remarkable changes at various time scales (Soomere et al., 2011). For example, open sea areas separated by only about $100 \mathrm{~km}$ may host completely different trends (Soomere and Räämet, 2011a). Moreover, the trends for average and extreme wave heights do not necessarily coincide (Soomere and Räämet, 2011b). Part of these changes apparently are related to the systematic increase in SouthWesterly winds over the last $40 \mathrm{yr}$ in the Northeastern (NE) part of the Baltic Sea (Jaagus and Kull, 2011). Such changes are a probable reason for a considerable intensification of coastal processes in the vicinity of Neva Bay, which was sheltered from predominant waves in the past (Ryabchuk et al., 2011).

Although the predominant SW winds usually excite the roughest wave conditions in the NE and Southeastern (SE) Baltic Proper (Schmager et al., 2008; Soomere et al., 2008), the wave climate in the SW Baltic is equally important. This 
region hosts extremely dense ship traffic that is confined to narrow fairways, and is thus particularly vulnerable with respect to severe weather conditions. Also, most of the SW Baltic Sea coasts are easily erodible. Thus, any change in the local wave regime may substantially impact their evolution.

The seminal collection addressing the climate in the Baltic Sea basin (BACC, 2008) only presents the very basic aspects of the wave climate. The resolution of the existing reference books (Lopatukhin et al., 2006; Schmager et al., 2008) and global wave data sets such as KNMI/ERA-40 Wave Atlas $\left(09.1957-08.2002,1.5^{\circ} \times 1.5^{\circ}\right)($ Sterl and Caires, 2005) is far too sparse for an adequate representation of the typical and extreme wave conditions in the southern part of the Baltic Sea. Information about the wave climate in this region is available mostly from numerical simulations (Gayer et al., 1995; Mietus and von Storch, 1997; Papliñska, 1999, 2001; Blomgren et al., 2001; Cieślikiewicz and Herman, 2002; Augustin, 2005; Cieślikiewicz and Papliñska-Swerpel, 2008; Schmager et al., 2008) and from relatively short-term measurement campaigns (Mårtensson and Bergdahl, 1987). Only very basic information about wave measurements carried out since 1991 at the Darss Sill and since 2002 in the Arkona Basin is available in the Helsinki Commission (HELCOM) documentation (e.g. Pettersson et al., 2010). Finally, longterm time series (since 1954) of visually observed wave parameters from the Lithuanian coast have been used in comparisons of the wave climate in the northern and southern Baltic (Kelpšaite et al., 2008, 2011; Zaitseva-Pärnaste et al., 2011).

Information about climatological changes in wave parameters in this area is controversial. A popular opinion in the 1980s-1990s was that the wave climate was becoming gradually more severe following the seemingly increasing storminess (Alexandersson et al., 1998). This view was qualitatively supported by the National Centres for Environmental Prediction and for Atmospheric Research (NCEP/NCAR) reanalysis that revealed a significant increase in the annual mean wind speed at $850 \mathrm{hPa}$ over the Baltic in 1953-1999 (Pryor and Barthelmie, 2003). The increase was most pronounced in the upper quartile of wind speeds and in the SW of the region. A clear increase was also noticed in the higher percentiles of wind speeds at the $10 \mathrm{~m}$ level (Pryor et al., 2005). Such an increase generally leads to a larger proportion of high waves. Somewhat surprisingly, it did not become evident in the wave fields in the Baltic Sea and was also not recognized in the adjacent North Sea (WASA Group, 1995, 1998). At some places even a long-term decrease in the frequency of severe wave conditions was found (Weisse and Günther, 2007).

Consistently with the above-described changes in wind speeds, wave reconstructions based on geostrophic winds indicated an increase in wave heights in the Arkona Basin since about 1970 (Räämet et al., 2010). The most prominent increase in the geostrophic wind speed (GWSP) occurred in wintertime (December-February) for the southern and central parts of the Baltic Sea: the GWSP increased by $\sim 1.5 \mathrm{~m} \mathrm{~s}^{-1}$ in $1989-2007$ compared to that in 1970-1988 (Lehmann et al., 2011). The spring season (March-May) hosts an increase in the GWSP by $0.5-1 \mathrm{~m} \mathrm{~s}^{-1}$ in the Baltic together with a change in the wind direction from SW to west. During autumn, however, the GWSP decreased by 1.5$2 \mathrm{~m} \mathrm{~s}^{-1}$ for the western and central parts of the Baltic Sea. Although there seems to be no overall increase in the GWSP in the entire Baltic region, the above turn in the wind direction apparently favours the increase in wave heights in the SW Baltic Sea. The wave height and period are often fetchlimited in this area and therefore frequently depend as much on the wind direction as on the wind strength.

We make an attempt to establish the basic features of the wave climate and its changes for the SW Baltic Sea. Longterm wave measurements are carried out at two locations of this region. A waverider has been operated by the HelmholtzZentrum Geesthacht (until 2010 the GKSS Research Centre) at the Darss Sill since 1991. Another wave recorder is operated by the Federal Maritime and Hydrographic Agency of Germany (BSH) at a station northwest of Cape Arkona since 2002. A short analysis of both the data sets is available in the HELCOM information sheets (e.g. Pettersson et al., 2010). The data set from the device at Cape Arkona only covered 9 years till now and is not considered in this paper.

The wave parameters at the Darss Sill in 1991-2010 are compared with two long-term hindcasts, performed for 1958-2002 (Augustin, 2005; Schmager et al., 2008) and 1970-2007 (Räämet and Soomere, 2010), respectively. We start with the description of the instrumentally recorded and numerically simulated data sets. The wave climate is discussed based on the distributions of the frequency of occurrence of different wave heights and periods. The temporal changes to the wave heights are analysed on daily, weekly, annual and decadal scales. The comparison focuses on a subset hourly wave recordings for the interval 1991-2002.

\section{Recorded and modelled data}

The $20 \mathrm{yr}$ long time series (1991-2010) from the Darss Sill is the most valuable source of the wave information in the SW Baltic. The waves have been measured with a surface following buoy (Seawatch Directional Waverider, Barstow et al., 1994) since 29 January 1991. The water depth at the site $\left(54^{\circ} 41.9^{\prime} \mathrm{N}, 12^{\circ} 42.0^{\prime} \mathrm{E}\right.$, Fig. 1$)$ is $20 \mathrm{~m}$. The buoy is moored using an anchor chain with a weight of about $500 \mathrm{~kg}$, a $15 \mathrm{~m}$ long rubbercord (diameter $35 \mathrm{~mm}$ ) and a $50 \mathrm{~m}$ long swimcord (diameter $20 \mathrm{~mm}$ ). The wave parameters are calculated onboard the buoy over $1600 \mathrm{~s}$ time series of surface displacement. From a variety of measured parameters we consider the significant wave height $H_{\mathrm{S}}$ (called simply wave height below) and the period $T_{-1}$ (called mean period) in what follows. 


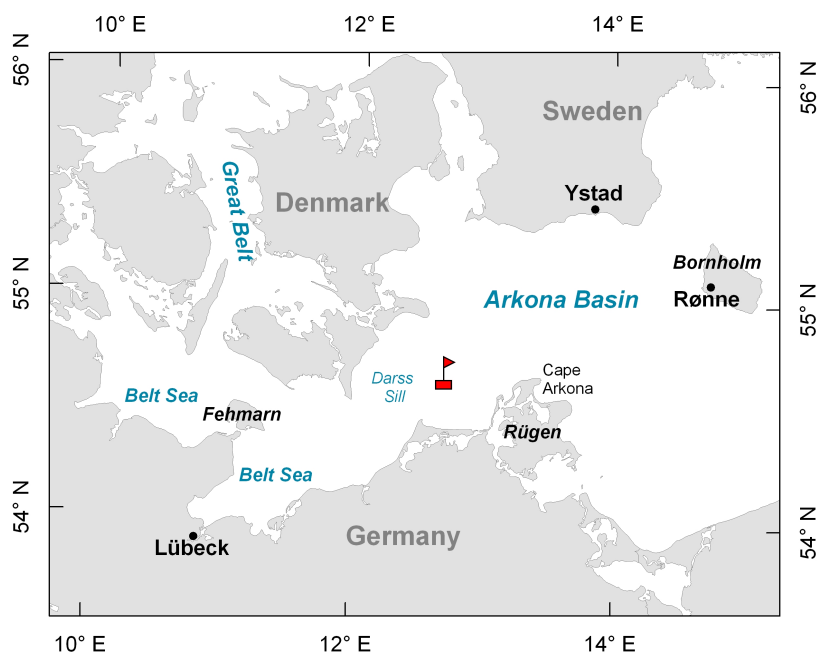

Fig. 1. Wave measurement sites at the Darss Sill and to the north of Cape Arkona.

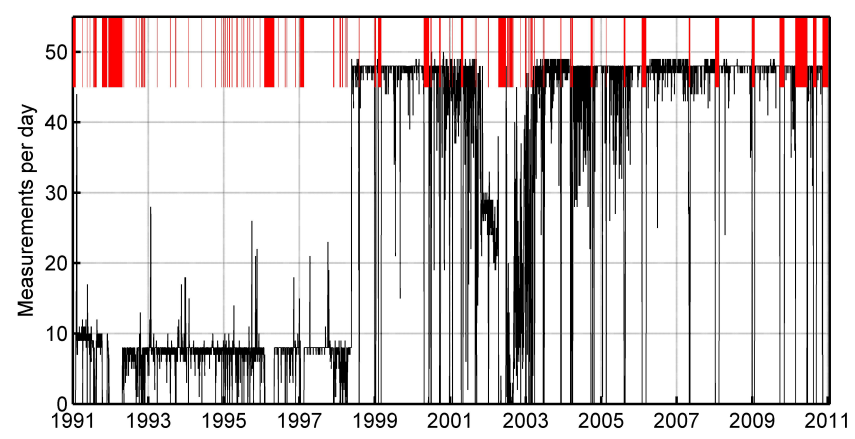

Fig. 2. Number of records per day at the Darss Sill in 1991-2010. The red lines at the top of the panel indicate days with no measurements.

A few records represent unrealistic situations (such as single peaks of wave height $>10 \mathrm{~m}$ or obviously incompatible height and period) and were excluded from the analysis. The pool of 190300 consistent wave records covers 7305 calendar days in 1991-2010. At least one record per day exists for 6198 days ( $\sim 85 \%$ of days). The data contains several longer gaps: 30 July-11 August, 16-18 August, 14 October-27 November 1991, 17 December 1991-23 April 1992, 1 February-1 May 1996 (caused by ice formation), 10 January-13 February 1997, May 2000, February 2006, October 2009, March-May and December 2010 (Fig. 2). The gaps are distributed unevenly over the calendar year (Fig. 3). There are very few gaps in June and July. The autumn season (September-beginning of December) is equally well represented. Typically, about $90-95 \%$ of days in these months are covered by at least one wave record. The lowest percentage (about $70 \%$ ) of days covered by measurements is at the end of December and in January-February and April.

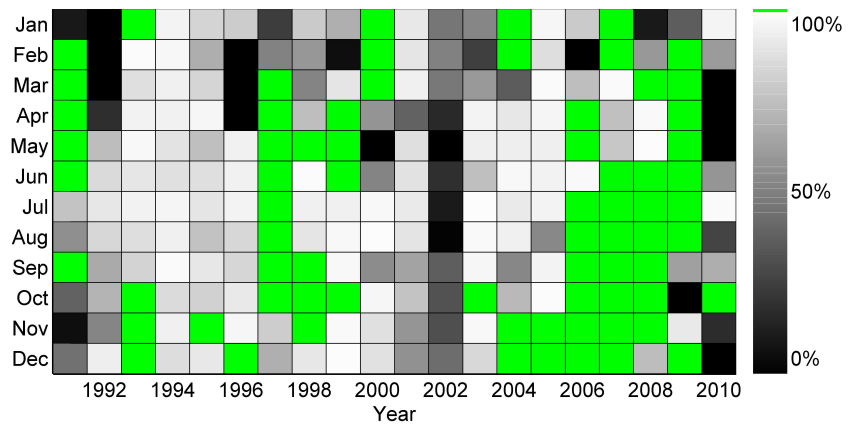

Fig. 3. Monthly average percentage of successful measurements. The expected number of measurements per day is 8 until May 1998 and 48 since then. The coverage $>99 \%$ is indicated in green.

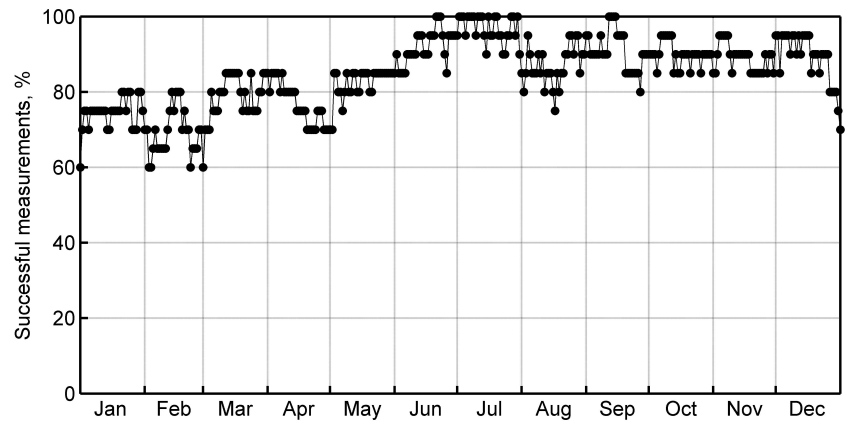

Fig. 4. Percentage of calendar days with at least one successful measurement in 1991-2010.

The number of records per day varies over time (Fig. 4). During the first years of measurements (1991-1997) the wave parameters were usually recorded 8 times a day at the main and intermediate synoptic times (00:00 UTC, 03:00 UTC, 06:00 UTC, 09:00 UTC, 12:00 UTC, 15:00 UTC, 18:00 UTC and 21:00 UTC). Starting from 19 May 1998 about 48 records a day (twice an hour) are available. The number of records fluctuates between almost zero and 50 a day in 2001-2003. Figure 3 characterizes the number of records in single months compared with the usual amount of records per day ( 8 or 48 ) for the particular month. The success rate is about $80 \%$ in 1991-1997 and about $77 \%$ in 1999-2010. In 1993 and 2007 this rate was $>95 \%$ whereas it was $53 \%$ in 1992 and as low as $28 \%$ in 2002.

The measured data is compared with two hindcasts. Both simulations used the third generation wave model WAM (Komen et al., 1994) and a regular grid covering the entire Baltic Sea with a spatial resolution of about $5.5 \mathrm{~km} \times 5.5 \mathrm{~km}$. The wave spectra were computed with a directional resolution of $15^{\circ}$ (24 directions) and for a set of logarithmically spaced frequencies with an increment of 1.1. For comparisons we use integrated wave parameters (significant wave height and mean period, available hourly) for a model grid point at $54^{\circ} 42^{\prime} \mathrm{N} ; 12^{\circ} 42^{\prime}$ E. For simplicity, we occasionally 
mention height or period, having in mind the integrated parameters.

The simulations differ by the time span, wind data, frequency range, treatment of wave field at open boundaries and ice cover. The first hindcast (called the AW simulations below) reflects the period of 1958-2002 (Augustin, 2005; Weisse et al., 2009). The forcing wind fields were derived from an atmospheric reconstruction using a regional atmosphere model (Feser et al., 2001) driven by the hourly winds from the NCEP/NCAR reanalyses (Kalnay et al., 1996; Kistler et al., 2001). At the lateral boundaries wave information from a corresponding North Sea hindcast (Weisse and Günther, 2007) was used. The model uses 28 frequency bins ranging from about 0.05 to $0.66 \mathrm{~Hz}$. The impact of ice was accounted for using monthly ice coverage from the BSH observations.

Another hindcast (called the RS simulations below) was performed for 1970-2007 (Räämet and Soomere, 2010). Differently from the above simulations, the WAM model was driven by adjusted geostrophic winds from the Swedish Meteorological and Hydrological Institute with a spatial resolution of $1^{\circ}$ and temporal resolution of 3 or 6 hours. The geostrophic wind speed was multiplied by 0.6 and the direction turned $15^{\circ}$ anti-clockwise to yield an estimate of the wind at the $10 \mathrm{~m}$ level. This approximation, equivalent to one of the options analysed in (Bumke and Hasse, 1989), is frequently used in the Baltic Sea region. Although stability questions of the air flow are completely ignored in this approximation, it leads to an acceptable reproduction of both circulation and wave patterns (Myrberg et al., 2010; Soomere and Räämet, 2011a, b). Wave propagation from the North Sea and the presence of ice were ignored. An extended frequency range up to about $2 \mathrm{~Hz}$ (wave periods down to $0.5 \mathrm{~s}$, 42 frequency bins) was used to ensure realistic wave growth rates in low wind conditions after calm situations (Soomere, 2005).

Each of these hindcasts reflects somewhat different features of waves. The AW simulations use relatively highresolution wind information. As they cover a comparatively narrow range of frequencies, they may fail to resolve highfrequency wave components. The RS simulations use lowresolution wind information but are specifically tuned to represent low and short waves that are frequent in sheltered and/or nearshore domains of the Baltic Sea.

\section{Wave climate}

A comparison of the measured data with the simulated sets is not straightforward because different data sets represent different time intervals. The simulated data sets are homogeneous but the recorded data set contains extensive gaps. Moreover, measurement instants vary and the number of records largely varies for different days. For this reason the analysis below primarily relies on a pool of 47078 hourly records in 1991-2002 and on the corresponding simulated data for the same time instants. These sets are called overlapping data in what follows. Alternatively, we use its subset of 26127 records at the main and intermediate synoptic times (called ST data below). This subset is considerably more homogeneous and less serially correlated than the hourly data. The entire pool of recorded data in 19912010 is only used to demonstrate that the results obtained from the above subsets well represent the long-term parameters of the wave climate and for the analysis of possible changes in the wave heights and periods. Occasionally we also compare measured and simulated data for different intervals to demonstrate that many features of the wave climate are very stable over decades.

\subsection{Average and extreme wave heights}

The average measured wave height $(0.76 \mathrm{~m})$ is almost the same for different subsets of records in 1991-2002 (Table 1). Therefore, the listed sources of inhomogeneities have a limited impact $(<0.2 \%)$ on the estimates of this quantity. Moreover, small variations $(\sim 1 \%)$ in the average wave height for largely different time intervals (1991-2002 and 1991-2010, Table 1) suggest that no long-term trend in wave heights exists at the study site.

The average hindcast wave height for the overlapping data is slightly larger, $0.846 \mathrm{~m}$ in the AW simulations and $0.798 \mathrm{~m}$ in the RS simulations. While the average for the RS simulations for 1970-2007 is almost the same, the long-term average for the AW simulations for 1958-2002 (0.836 m) indicates a slight increase in the wave intensity since the mid1990s.

The differences between the measured and hindcast average wave height primarily reflect the quality of the driving winds. The AW simulations with downscaled NCEP/NCAR reanalysed winds overestimate the wave heights by $\sim 8 \%$. The bias $(0.085 \mathrm{~m})$ and root-mean-square $(\mathrm{rms})$ difference $(0.41 \mathrm{~m})$ of the recorded and AW-hindcast wave heights are about the same as reported by Cieślikiewicz and PapliñskaSwerpel (2008) for a few months in 1997-1998 at Niechorze near the Polish coast ( $0.09 \mathrm{~m}$ and $0.36 \mathrm{~m}$, respectively).

The RS simulations have been shown to underestimate wave heights by about $15 \%$ for the coastal sites of the northern Baltic Proper and at the entrance to the Gulf of Finland (Räämet and Soomere, 2010). This indicates that the adjusted GWSP is slightly underestimated for the northern Baltic. A relatively small bias $(0.042 \mathrm{~m})$ of the RS-hindcast wave heights at the Darss Sill indicates that the resulting wind speeds are an adequate approximation for the SW Baltic Sea. The rms difference between the RS-hindcast and measured data is about $0.72 \mathrm{~m}$. This value is still common for other locations of the Baltic Sea such as Lubiatowo at the Polish coast (0.62 m, Cieślikiewicz and Papliñska-Swerpel, 2008) or Almagrundet in the northern Baltic Proper $(0.72 \mathrm{~m}$, Räämet et al., 2009). 
Table 1. Basic parameters of the wave climate at the Darss Sill: long-term significant wave height $H_{\mathrm{S}}$, median wave height, $90 \%$-ile, $95 \%$-ile, $99 \%$-ile, and the shape $(k)$ and scale $(b)$ parameters of the corresponding Weibull distributions. The parameters are calculated for all existing data (All data), main and intermediate synoptic times (ST), daily means, all data in 1991-2002, and for the overlapping data set (Overlap).

\begin{tabular}{lccccccccccc}
\hline & \multicolumn{4}{c}{ Measurements at the Darss Sill } & \multicolumn{3}{c}{ AW simulations } & \multicolumn{2}{c}{ RS simulations } \\
\hline & All data & ST & Daily means & $1991-2002$ & Overlap & All & 1991-2002 & Overlap & All & $1991-2002$ & Overlap \\
\hline$H_{\mathrm{S}}$ & 0.760 & 0.754 & 0.761 & 0.754 & 0.756 & 0.836 & 0.844 & 0.846 & 0.799 & 0.796 & 0.798 \\
Median & 0.65 & 0.65 & 0.67 & 0.64 & 0.64 & 0.676 & 0.703 & 0.684 & 0.60 & 0.60 & 0.59 \\
$90 \%$ & 1.43 & 1.42 & 1.36 & 1.43 & 1.43 & 1.61 & 1.64 & 1.64 & 1.58 & 1.62 & 1.60 \\
$95 \%$ & 1.69 & 1.67 & 1.58 & 1.70 & 1.70 & 1.97 & 1.97 & 1.98 & 2.00 & 2.02 & 2.01 \\
$99 \%$ & 2.23 & 2.15 & 2.03 & 2.30 & 2.30 & 2.74 & 2.75 & 2.76 & 2.89 & 2.92 & 2.88 \\
$k$ & 1.604 & 1.619 & 1.811 & 1.586 & 1.589 & 1.491 & 1.555 & 1.515 & 1.376 & 1.366 & 1.361 \\
$b$ & 0.848 & 0.842 & 0.855 & 0.840 & 0.843 & 0.926 & 0.952 & 0.938 & 0.874 & 0.883 & 0.871 \\
\hline
\end{tabular}

The median wave height for the overlapping data is $0.64 \mathrm{~m}$. The thresholds for $10 \%, 5 \%$ and $1 \%$ of the highest wave heights (called $90 \%$-ile, $95 \%$-ile and $99 \%$-ile in what follows) are $1.43 \mathrm{~m}, 1.68 \mathrm{~m}$ and $2.22 \mathrm{~m}$, respectively. The insignificant variation of similar values for other subsets of measured data (Table 1) indicates that the frequency of occurrence of different wave heights is represented well by any of these subsets.

An analysis of extreme wave conditions at the Darss Sill is presented in (Soomere and Kurkina, 2011) and we bring here only a few key facts. The seas with $H_{\mathrm{S}}>2 \mathrm{~m}$ are already very severe in this area and occur during about $1 \%$ of the time, or during $\sim 100$ hours $\mathrm{yr}^{-1}$. A similar threshold for the open Baltic Proper is $4 \mathrm{~m}$ (Kahma et al. 2003). Waves higher than $3 \mathrm{~m}$ occur with a frequency of about $0.15 \%$, that is, during $\sim 13$ hours $\mathrm{yr}^{-1}$. Waves higher than $4 \mathrm{~m}$ were measured in three storms during the $20 \mathrm{yr}$ under study. In a long wave storm on 10-11 January 2010, the wave height was close to $4 \mathrm{~m}$ during about $30 \mathrm{~h}$. The largest reliably recorded wave height $(4.46 \mathrm{~m})$ occurred on 3 November 1995 in a strong NE storm when the AW-hindcast wave height was $3.92 \mathrm{~m}$. The maximum numerically simulated wave height $(6.23 \mathrm{~m}$ in the AW simulations) occurred on 26 January 1990.

\subsection{Diurnal variations and daily mean wave heights}

The large number of available measurements makes it possible to evaluate the magnitude of diurnal variations in the wave height. Such variations play a role in areas affected by strong breezes where they may lead to an increased level of cross-seas and pose a certain danger to smaller vessels (Vethamony et al., 2011). The measurements at the Darss Sill are distributed almost evenly over the day (Fig. 5a). Only the main and intermediate synoptic times contain more measurements because the recordings mostly exist for these times in 1991-1998. This difference does not become evident in the diurnal course in the wave height (Fig. 5b). On average, wave heights are largest over night (02:00-07:00 UTC) and late evening between 18:00 and 22:00 UTC. The extension of the diurnal variation is $0.026 \mathrm{~m}$ (about $\pm 1.7 \%$ from the average of $0.76 \mathrm{~m}$ ) and standard deviation of hourly values is $\sigma=0.0067 \mathrm{~m}$. In single months (February, April-May, September, October) the relative daily course is much larger, up to $\pm 7.6 \%$ ( $\sigma=0.021 \mathrm{~cm}$, mean wave height $0.57 \mathrm{~m})$ in May. There is, however, no statistically significant pattern in these variations in single months or over selected seasons.

A combination of the changing number of records per day with a pronounced diurnal variation may affect the estimates of the climatological parameters of wave fields. The above analysis suggests that these issues insignificantly impact such estimates based on the Darss Sill data set. The associated inhomogeneity can be removed by using the daily average wave height. Doing so is important if the number of records a day varies seasonally (Zaitseva-Pärnaste et al., 2009; 2011). This procedure usually leads to adequate estimates of the average wave parameters but may significantly alter their distributions. The average and median daily mean wave height $(0.76 \mathrm{~m}$ and $0.67 \mathrm{~m}$, respectively) almost coincide with similar values for the different subsets of recordings. The higher percentiles for the daily mean wave heights (Table 1), however, differ substantially from similar values calculated for single records. This is not unexpected: the use of daily means naturally leads to an increase in the proportion of medium values at the expense of very low and very high waves. This difference is further discussed below.

\subsection{Distributions of wave heights}

The distribution of the occurrence of measured wave heights at Darss Sill (Fig. 6) resembles those for the open parts of the Baltic Proper (Kahma et al., 2003; Broman et al., 2006). Most frequent are seas with $0.25 \leq H_{S}<0.375 \mathrm{~m}$, that is, well below the median value. The shape parameter $k=1.569$ of the corresponding Weibull distribution shows that it is quite far from a Rayleigh distribution. This empirical distribution almost coincides with similar ones calculated for the entire data set and for the main synoptic hours (Fig. 6). The values for single bins differ by less than \pm 0.3 and \pm 0.44 per 

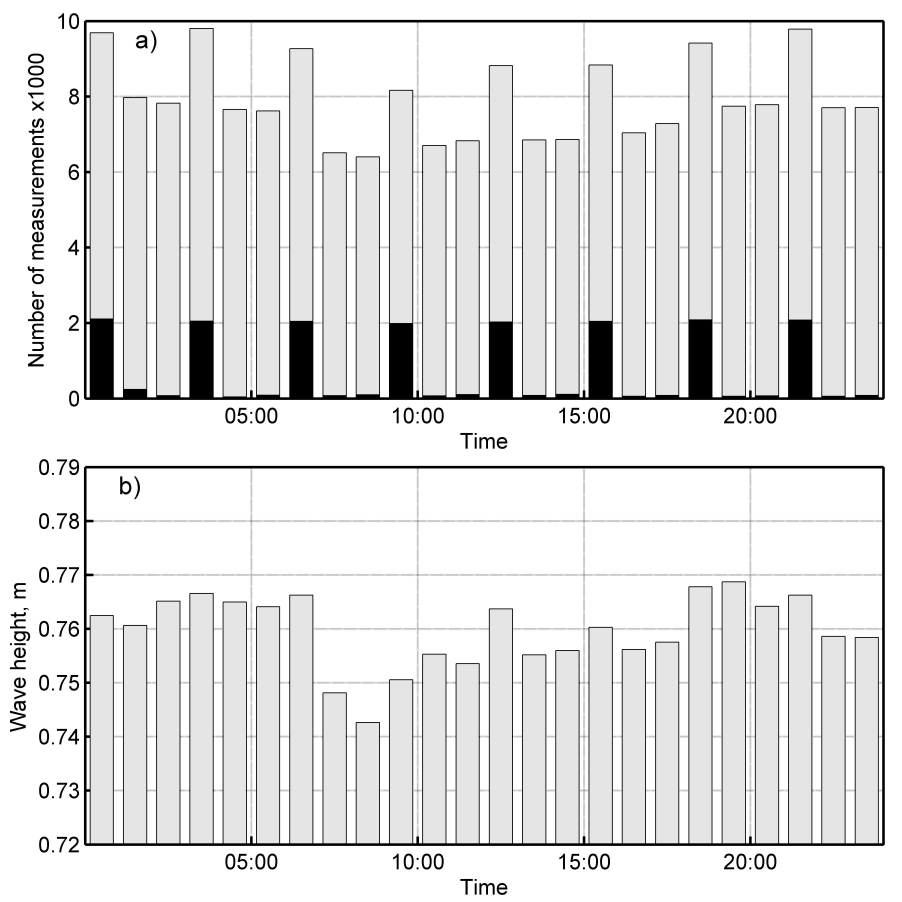

Fig. 5. (a) Number of measurements each hour (filled bars indicate the number of measurements before 19 May 1998); (b) diurnal variation in the average wave height.

cent, respectively. This match strengthens the conjecture that the largely varying number of measurements a day insignificantly affects the estimates of the parameters of the wave climate from the particular data set.

The hindcasts adequately reproduce the frequency of seas with $0.5 \leq H_{S}<1.5 \mathrm{~m}$ but tend to overestimate the proportion of rougher wave fields with $H_{\mathrm{S}}>1.5 \mathrm{~m}$. The fraction of low waves $\left(H_{\mathrm{S}}<0.125 \mathrm{~m}\right)$ is very small (Fig. 7). The largest discrepancy between the recorded and hindcast waves occurs for the range of wave heights of $0.125-0.5 \mathrm{~m}$. Both simulations underestimate the frequency of low waves $(0.125-0.375 \mathrm{~m})$ and overestimate the frequency of seas with $0.375 \leq H_{S}<0.5 \mathrm{~m}$. As a result, the overall maximum of the modelled distributions is at $0.375 \leq H_{S}<0.5 \mathrm{~m}$ like in the similar distribution for daily mean wave heights. Still, both the models adequately reproduce the overall proportion of wave fields with $H_{\mathrm{S}}<0.5 \mathrm{~m}$ : the measured data contain $37 \%$ of such fields, the AW and RS hindcasts $33 \%$ and $41 \%$, respectively.

The difference between the empirical and simulated distributions can be additionally quantified using the corresponding Weibull distributions. This comparison once more indicates that the AW simulations (shape parameter $k=1.515$ ) reasonably reproduce the basic features of the wave climate at the Darss Sill. A clearly smaller value of $k=1.36$ (Table 1) suggests that the RS-hindcast distribution of wave heights is considerably wider than the measured one.
As expected, the daily mean wave height has a clearly smaller frequency for the lowest and the largest values. The central part of its distribution (Fig. 6) is almost flat and daily mean heights of $0.25-0.625 \mathrm{~m}$ occur with an almost equal frequency. This is balanced by a somewhat larger frequency of seas with $0.375 \leq H_{S}<1.25 \mathrm{~m}$ than in the distribution for single records. The discussed differences are vividly reflected in the relevant Weibull distributions. The distribution for daily mean wave heights has a clearly larger shape parameter $(k=1.8112)$ than similar distributions for single measurements. This dissimilarity would lead to obvious differences in the estimates for the probabilities of occurrence of severe seas.

Interestingly, the distributions of hindcast wave heights calculated for the overlapping data and for the entire hindcast period (1958-2002 and 1970-2007, respectively) almost coincide. For the AW simulations the difference is the largest (about 1 per cent) for very low waves $\left(H_{\mathrm{S}}<0.125 \mathrm{~m}\right)$ and is below 0.5 per cent for all other bins. The RS simulations reveal the largest difference ( 0.77 per cent) for the range of $0.25-0.375 \mathrm{~m}$. This feature suggests that the shape of this distribution exhibits very limited changes over decades.

\subsection{Distributions of periods}

The distribution of the occurrence of mean wave periods $\left(T_{-1}\right.$, Fig. 8$)$ has a general bell shape, slightly skewed towards shorter waves. The frequent presence of waves with periods $3-4 \mathrm{~s}$ is typical for semi-sheltered and coastal areas 


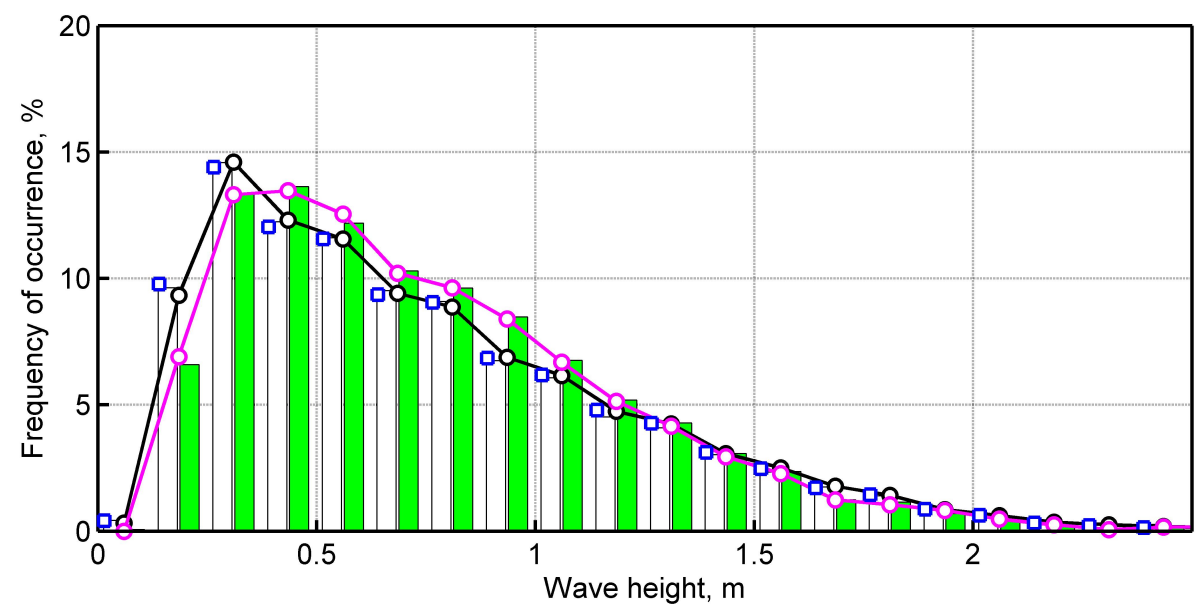

Fig. 6. Frequency of occurrence of different measured wave heights in the overlapping data set (white bars, 1991-2002), at main and intermediate synoptic times (blue squares, 1991-2010), in all measurements (black circles, 1991-2002) and in daily average wave heights in 1991-2002 (magenta circles) and in 1991-2010 (green bars).

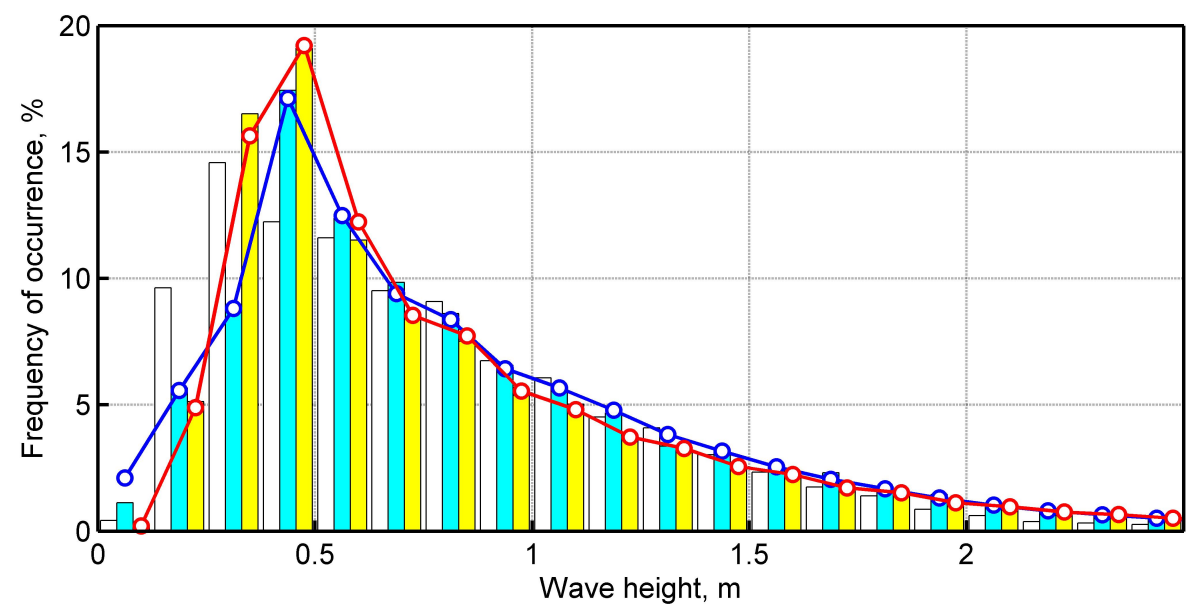

Fig. 7. Frequency of occurrence of different wave heights in the overlapping data set in 1991-2002 based on measurements (white bars representing the same set as in Fig. 6), AW simulations (cyan bars) and RS simulations (yellow bars). Blue and red circles correspond to the entire set of AW (1958-2002) and RS (1970-2007) simulations, respectively.

of the Baltic Sea (Soomere, 2008; Soomere and Räämet, 2011b). Interestingly, wave periods are concentrated in quite a narrow range. Waves with periods of about $3 \mathrm{~s}$ are the most frequent. About $50 \%$ of all seas are within the period range of 2.7-3.6 s and about $70 \%$ in the range of 2.6-4 s. The fraction of seas with periods exceeding $4,5,6$, and $7 \mathrm{~s}$ is also relatively low: $10.85 \%, 0.55 \%, 0.075 \%$ and $0.007 \%$, respectively. This is not unexpected as a small fraction of remote swell is typical for the Baltic Sea (Broman et al., 2006; Soomere, 2008).

The almost total absence of seas with mean periods below $2 \mathrm{~s}(\sim 0.02 \%)$ in wave records is not realistic for smaller sub-basins of the Baltic Sea. It evidently stems from the limitation of the waverider. According to the manufacturer, the device captures wave periods $1.6-30 \mathrm{~s}$. The fraction of seas with mean periods about $1-2 \mathrm{~s}$ is substantial in some semisheltered areas of the Baltic Sea (Zaitseva-Pärnaste et al., 2009). A very large proportion (up to $40 \%$ ) of waves with periods below $2.5 \mathrm{~s}$ seems to be only characteristic to coastal areas with a depth below $10 \mathrm{~m}$. An appreciable frequency (about $5 \%$ ) of such waves has been documented also for deeper locations of the open Baltic Proper such as Bogskär in 1982-1986 (Kahma et al., 2003; Soomere, 2008). Although the water depth at the Darss Sill site is $20 \mathrm{~m}$, the fetch length for many directions is quite limited (Fig. 1) and it is probable that the fraction of wave fields with periods below $2.4 \mathrm{~s}$ is underestimated in the measurements. It is likely that the period of such wave fields is simply overestimated by the waverider. This distortion may lead to a certain overestimation of seas 


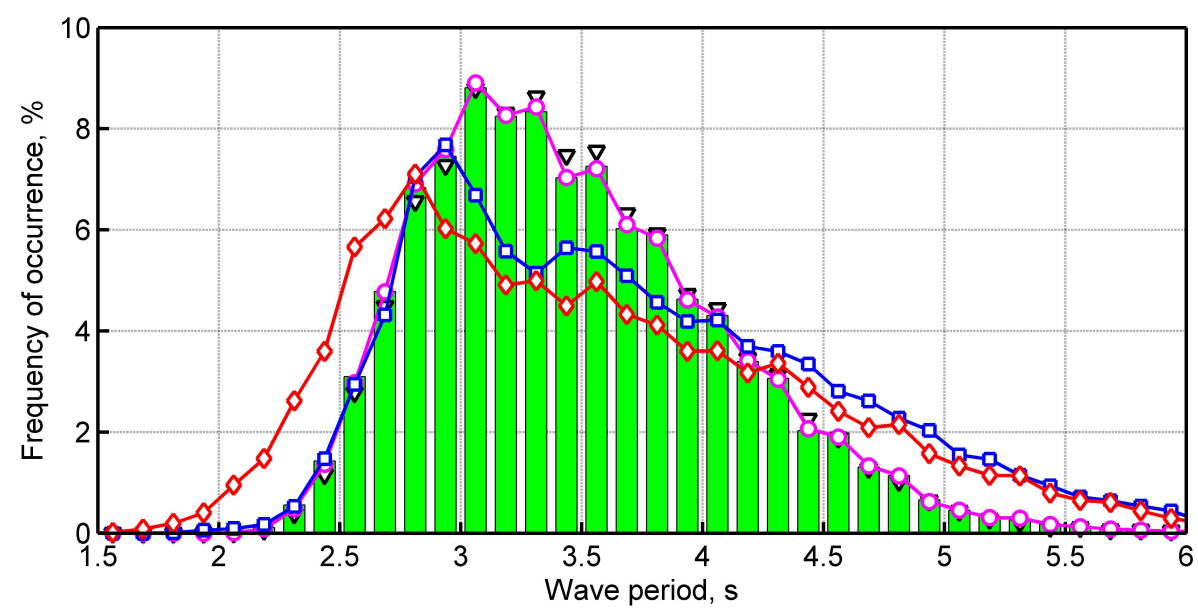

Fig. 8. Frequency of occurrence of different mean wave periods $\left(T_{-1}\right)$ in the overlapping data set of measurements (bars) and AW (blue squares) and RS (red diamonds) simulations in 1991-2002. Triangles show the distribution of all recorded wave data in 1991-2010.

with slightly longer periods and may artificially enhance the peak for periods around $3 \mathrm{~s}$ in Fig. 8.

The hindcast distributions of wave periods also have a steep slope for mean periods below $3 \mathrm{~s}$. A very small fraction of waves with $T_{-1}<2.2 \mathrm{~s}$ in the AW hindcast is also not realistic and apparently reflects the limited frequency range (periods $>1.5 \mathrm{~s}$ ) of the model. The RS simulations cover frequencies periods down to $0.5 \mathrm{~s}$ and advocate a considerable fraction of waves with periods of 2-2.5 $\mathrm{s}$.

All distributions in question have a two-peak appearance. The above suggests that the main peak at $3 \mathrm{~s}$ may be to some extent enhanced at the expense of seas with smaller periods for the measured data and for the AW simulations. The presence of a secondary peak at periods of $\sim 3.5 \mathrm{~s}$ (which is more clearly evident in the hindcast distributions) may be associated with a superposition of two wave regimes in the Darss Sill region: locally excited waves with typical mean periods of $\sim 3 \mathrm{~s}$ and wave systems with periods of $>3.5 \mathrm{~s}$ approaching from the Arkona Basin and Baltic Proper.

The modelled distributions considerably (by $\sim 30 \%$ ) underestimate the fraction of seas with periods of 3-4s and substantially (up to three times for selected frequency bins) overestimate the fraction of periods $>4 \mathrm{~s}$. Both simulations suggest that even periods $>6 \mathrm{~s}$ may occur with an appreciable frequency. Waves with such periods cannot be generated locally by predominant westerly winds because of limited fetch. Therefore, a large proportion of long waves according to hindcasts probably reflects an overestimation of the chances for remote swells formed in the Baltic Proper to penetrate to the Darss Sill area.

Similarly to the distributions of wave heights, the distributions of periods for different subsets of measured data almost coincide (Fig. 8). The same conclusion is true for the simulated distributions. Moreover, the distributions for the entire AW and RS hindcasts (not shown) practically coincide with the ones presented in Fig. 8: the differences are $<0.5$ per cent for single frequency bins. Consequently, the distribution of wave periods, either measured or calculated, is stable on a decadal scale at this site. This conjecture matches a conclusion of (Soomere and Räämet, 2011b) about very limited changes in the modelled wave periods in the Baltic Sea.

\subsection{Joint distributions of heights and periods}

The distribution of the occurrence of measured combinations of wave heights and periods (Fig. 9; sometimes called scatter diagrams) has a shape generally characteristic of the Baltic Sea conditions (Soomere, 2008). These combinations are typically concentrated along the line corresponding to saturated wave fields with a Pierson-Moskovitz (PM) spectrum. This feature is particularly apparent for relatively severe seas, with $H_{\mathrm{S}}>2 \mathrm{~m}$. It evidently stems from the small size of the Belt Sea and the Arkona Basin where most of the wave fields develop in fetch-limited conditions. Therefore, their parameters should generally follow a JONSWAP spectrum (Komen et al., 1994), for which also the wave height increases proportionally to squared period.

The branch of low and long waves, usually the predominant one in the open ocean, is almost missing in Fig. 9. Consequently, swell excited in the Baltic Proper infrequently reaches the study area. Remotely excited waves are only represented in a few occasions with $H_{\mathrm{S}}<1.2 \mathrm{~m}$ and periods of 5-6s. The relevant storms are evidently localised in the southern Baltic because storms covering the entire Baltic Sea usually excite even longer swells (Soomere, 2008; Soomere and Räämet, 2011b).

Figure 9 also reflects several above-discussed limitations of the measurements and simulations. First of all, waves with periods $<2 \mathrm{~s}$ are missing in the measured data. It is likely that the fraction of short waves is occasionally underestimated and, consequently, the mean wave period is overestimated. This practice may lead to a certain overestimation of the 

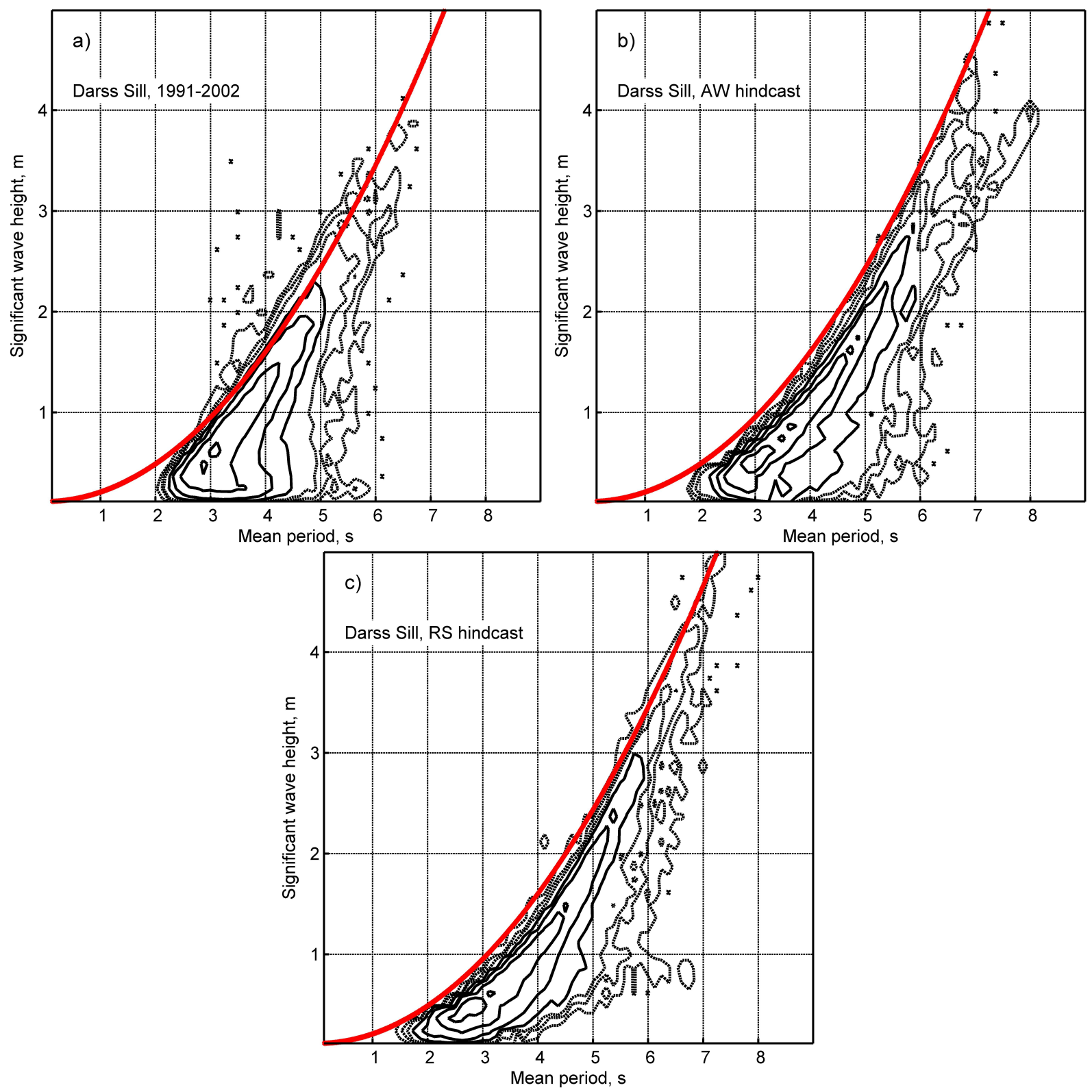

Fig. 9. The number of different combinations of wave heights and periods in the overlapping data set of measurements at the Darss Sill (a) and AW (b) and RS (c) simulations. The red line indicates the parameters of wave fields with a Pierson-Moskowitz (PM) spectrum. The peak period $T_{p}$, mean period $T_{-1}$ and significant wave height of such seas satisfy the relationships $T_{p}=8.5 \pi \sqrt{H_{\mathrm{S}} /(4 g)}$ and $T_{p} \approx 1.2965 T_{-1}$, where $g$ is the gravity acceleration. The contour lines are drawn for 1, 3, and 10 cases (dashed) and 33, 100, 330, and 1000 cases (solid). The resolution for both wave heights and periods is 0.125 .

fraction of low waves $\left(H_{\mathrm{S}}<0.5 \mathrm{~m}\right)$ with periods of $3-4 \mathrm{~s}$ in Fig. 9. The AW simulations (Fig. 9b) indicate a slightly larger proportion of seas with periods $<2$ s but apparently fail to correctly capture some of such seas because only periods $>1.5 \mathrm{~s}$ are accounted for. The wave periods in the RS simulations extend down to about $0.5 \mathrm{~s}$ and the results advocate the presence of a considerably larger fraction of short-wavedominated seas (Fig. 9c).
The best match of all distributions occurs for wave heights in the range of 1-2 $\mathrm{m}$. The measured and RS-hindcast distributions are quite similar for wave heights $>2 \mathrm{~m}$. Only the modelled extreme waves are somewhat higher than the measured ones. The AW simulations suggest that in a few cases severe waves with $H_{\mathrm{S}} \sim 3-4 \mathrm{~m}$ and periods of 6-8 s (but with steepness smaller than for similar wave systems with a PM spectrum) have entered the area in question. This branch is less clearly evident in the RS simulations. All distributions 
are similar in the region of severe seas with $H_{\mathrm{S}}>2 \mathrm{~m}$ and suggest that one should expect steep severe seas with a minimum amount of longer wave components at this site during strong storms. Consistently with Fig. 8, the hindcasts overestimate the fraction of seas with periods $5-6 \mathrm{~s}$ and $H_{\mathrm{S}} \approx 1 \mathrm{~m}$.

Lopatukhin et al. (2006) suggest that such scatter diagrams are a useful tool for roughly estimating the combinations of wave heights and periods in the strongest storms over many decades and for verifying whether the hindcast extreme wave parameters are realistic. The diagrams in Fig. 9 suggest that, according to the measurements, the roughest seas at the Darss Sill site, which occurred once in $20 \mathrm{yr}$, may have wave heights slightly exceeding $4 \mathrm{~m}$ and the mean period of about $7 \mathrm{~s}$. The RS simulations suggest the roughest seas have the same mean period but wave heights close to $5 \mathrm{~m}$. The AW simulations suggest that in one "population" of strongest storms, the wave height and may reach about $4.5 \mathrm{~m}$ and period is also $7 \mathrm{~s}$. The most severe representative of another "population" of storms would apparently have slightly lower wave heights $(\sim 4.3 \mathrm{~m})$ but the mean period would be $\sim 8 \mathrm{~s}$. These estimates roughly match the parameters of the measured extreme seas: the mean wave period was $6.6 \mathrm{~s}$ in the strongest wave storm in November $1995\left(H_{\mathrm{S}}=4.46 \mathrm{~m}\right)$ and $6.1 \mathrm{~s}$ in two occasions in February 2005 and January 2010 when the wave height was $4.01 \mathrm{~m}$.

\section{Seasonal and long-term variations in wave heights}

An extensive seasonal course of (monthly mean) wave heights (Fig. 10) is a well-known feature of the Baltic Sea wave fields (BACC, 2008; Schmager et al., 2008). The potential impact of a different number of records a day on this course was minimized by calculating first the daily mean wave heights. This seasonal cycle follows a similar course of wind speed in the area in question, with a calm period in April-August and November-February as windy months (Mietus, 1998).

Recent research has revealed a major shift of stormy winds from late autumn to winter months (Lehmann et al., 2011). This is accompanied by a certain change to the wind direction. In order to establish whether and how these changes become evident at the Darss Sill, we calculated monthly mean wave heights for five $4 \mathrm{yr}$ intervals. The resulting courses follow the monthly course of the percentage of high winds at Lighthouse Kiel (Lehmann et al., 2011). In average, the highest waves are present in January and February and even a minor local maximum is clearly evident in June. While there are certain fluctuations in the wave heights for different $4 \mathrm{yr}$ periods, wave activity has been continuously high in February. Interestingly, two courses in question (for 19911994 and 2007-2011) closely follow the seasonal course of high winds of (Lehmann et al., 2011), while for several other intervals the average wave heights in November and December exceed those in January.

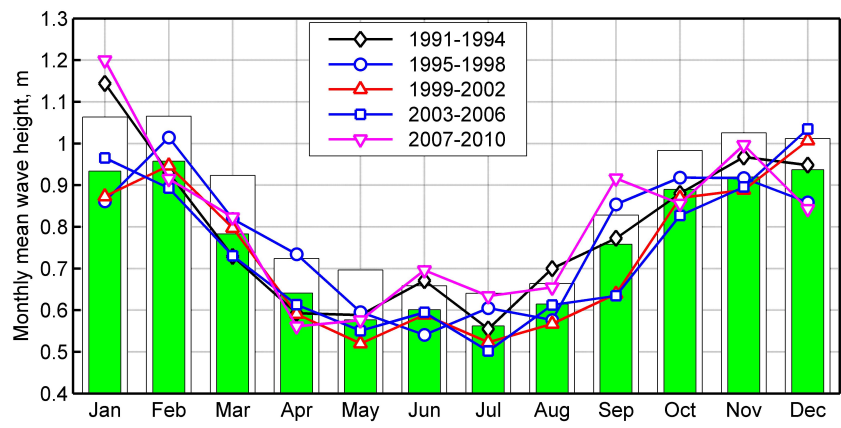

Fig. 10. Recorded (green bars) and AW-hindcast (white bars) monthly mean wave heights at Darss Sill for the overlapping data set in 1991-2002 and for recorded monthly mean wave heights for four-year intervals. Note that green bars only represent the average of three 4 yr intervals covering the years 1991-2002.

A recent analysis of historical visual observations has revealed substantial variations on weekly scales in the mean wave height for each calendar day in the northern part of the Baltic Sea, some of which were similar at sites separated by $100 \mathrm{~s}$ of $\mathrm{km}$ (Soomere et al., 2011). The annual course of this quantity for the Darss Sill (not shown) also contains substantial weekly-scale fluctuations with a magnitude (up to $0.4 \mathrm{~m}$ ) comparable with that of the usual seasonal course. Selected weeks of the calmest months (May-July) may host seas that are, on average, as severe as typical wave fields in windy months. Moreover, there apparently exist systematic variations in the wave activity within the transitional months (March-April and September-October). The pattern of weekly-scale variations apparently is mostly random at the Darss Sill and does not persist over longer time intervals.

The measured annual mean wave heights vary from $0.68 \mathrm{~m}$ up to $0.89 \mathrm{~m}$ (from $-12 \%$ to $+16 \%$ of the average) at the Darss Sill in 1991-2010 (Fig. 11a). The standard deviation (std) of the annual values is $\sigma=0.057 \mathrm{~m}$. The hindcast annual mean wave heights vary within a comparable range, from $0.74 \mathrm{~m}$ to $0.94 \mathrm{~m}$ (about $\pm 12 \% ; \sigma=0.066 \mathrm{~m}$ ) in the AW simulations and from 0.70 to $0.94 \mathrm{~m}(\sigma=0.051 \mathrm{~m})$ in the RS simulations. This range of variations apparently characterises the particular site. The above analysis has shown that it is sheltered from many storms that occur in the Baltic Proper. Wave parameters here are mostly determined by the local wind speed and fetch length; and these do not vary substantially.

The hindcast annual mean wave heights differ reasonably (by $<15 \%$ ) from the measured values. Neither of the simulations adequately represents the interannual variations in wave heights. The output of the RS simulation is even in antiphase with respect to the measured data for a few years (e.g. 1996 and 1997). Relatively high waves were recorded around 1995 and 2005 and wave activity was lower at the turn of the century. Such a manner of changes qualitatively 

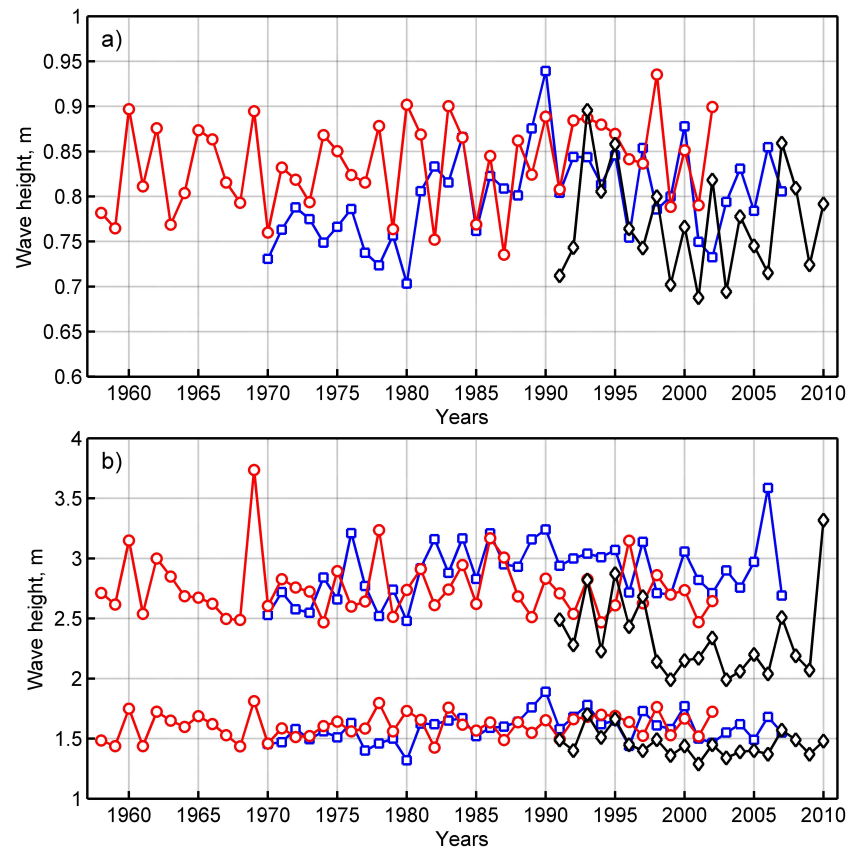

Fig. 11. Long-term course of annual characteristics of wave fields at the Darss Sill: (a) annual mean wave height; (b) annual $90 \%$-iles (lower set of markers) and 99\%-iles (upper set of markers). Diamonds show measured waves, circles represent the AW simulations and squares show the RS simulations.

matches the course of visually observed data at the Lithuanian coast (Zaitseva-Pärnaste et al., 2011). The variance of the annual mean wave heights is, however, so large that no firm conclusions can be drawn.

The measured data exhibit a weak decrease (about $9 \mathrm{~mm} /$ decade) in the annual mean wave height. The overall linear decrease $(0.018 \mathrm{~m}$ in $20 \mathrm{yr})$ is much smaller than the std of the annual wave height and the associated trend is far from being statistically significant. The simulated data sets match this decrease for the overlapping time interval $(33 \mathrm{~mm} /$ decade in the measurements in 19912002), for which the AW simulations show a weak decrease ( $12 \mathrm{~mm} /$ decade) and the RS simulations reveal a much steeper decrease $(54 \mathrm{~mm} /$ decade $)$. Given the relatively large variance of annual mean wave heights it is not surprising that none of these trends is statistically significant.

The full sets of simulated data show, however, a weak increase: the AW hindcast by $9 \mathrm{~mm} /$ decade for 1958-2002 and the RS hindcast by $17 \mathrm{~mm} /$ decade for $1970-2007$. The strongest decadal-scale trend $(61 \mathrm{~mm} /$ decade $)$ is evident in the RS simulations for 1970-1990 but is still far from being statistically significant.

The behaviour of the annual values of the $90 \%$-iles and $99 \%$-iles of recorded wave parameters (Fig. 11b) is qualitatively similar to that of the annual average wave height. The percentiles exhibit a larger interannual variability
( $\sigma=0.10 \mathrm{~m}$ and $\sigma=0.35 \mathrm{~m}$ for the $90 \%$-iles and $99 \%$-iles, respectively) and relatively high peaks (up to $40 \%$ higher than the average values for the $99 \%$-iles). The $90 \%$-ile decreased at a rate of $56 \mathrm{~mm} /$ decade and the $99 \%$-ile at a rate of $67 \mathrm{~mm} /$ decade, respectively. Notice that the latter rate would have been considerably larger without the evident peak in 2010 (Fig. 11b). These changes are also not significant.

The match between the measured and hindcast higher percentiles is not as good as the match between the annual mean wave heights. The models reasonably reproduce the typical values of the $90 \%$-ile but tend to considerably overestimate the $99 \%$-ile (by up to $40 \%$ for some years). This is consistent with a tendency of the WAM model to overestimate wave heights in severe seas in the southern Baltic (Cieślikiewicz and Papliñska-Swerpel, 2008).

The RS simulations suggest that both $90 \%$ and $99 \%$ percentiles have slightly increased (by 30 and $74 \mathrm{~mm} /$ decade, respectively) since the $1970 \mathrm{~s}$. The AW simulations reveal almost no trend since the 1950s (an increase by $14 \mathrm{~mm} /$ decade in the $90 \%$-ile and a decrease by $18 \mathrm{~mm} /$ decade in the $99 \%$ ile). Again, none of the discussed trends are statistically significant.

\section{Conclusions and discussion}

The wave climate in the Darss Sill area resembles the wave climate in other sub-basins of the Baltic Sea. It exhibits a persistent and substantial seasonal variation in wave heights in a combination of transient fluctuations of the same level on weekly scales over all months. On the one hand, a considerable diurnal variation in the wave height suggests that the seas here are noticeably influenced by coastal effects. A combination of the relatively modest long-term average wave height $(0.76 \mathrm{~m})$ and the heights of most typical seas $(0.25-0.5 \mathrm{~m})$ with the predominance of relatively short waves is characteristic to the nearshore areas of the Baltic Sea (Soomere, 2008). A specific feature here is the narrow range for typical wave periods (2.6-4 s): much longer waves may frequently occur in other large sub-basins of the Baltic Sea such as the Gulf of Finland, Gulf of Riga or Bothnian Sea. Finally, extreme wave heights of the order of $H_{\mathrm{S}} \approx 4 \mathrm{~m}$ once a decade are similar to those that occur in the listed sub-basins. On the other hand, a small fraction of low waves $\left(H_{\mathrm{S}}<0.25 \mathrm{~m}\right)$ indicates that the site cannot be considered as a coastal one (in which calm conditions are frequent even at the coasts of the Baltic Proper). The distributions of the occurrence of different wave heights are also characteristic for the parameters of waves in the open Baltic Sea.

Certain formal trends may be identified in the measured data. The trend for the annual mean wave height is fairly small $(-9 \mathrm{~mm} /$ decade $)$ and reaches -56 and $-67 \mathrm{~mm} /$ decade for $90 \%$-ile and $99 \%$-ile, respectively. The variance in the data is, however, so extensive that none of these trends is even close to a statistically significant one. 
Therefore, it is safe to say that the recorded wave data exhibit no indication about any changes in the local wave height over two decades. Analysis of the hindcast data additionally suggests that the wave height has undergone no substantial changes in this area since the 1950s.

The appearance of the measured distribution of wave periods suggests that the measurement site is effectively sheltered from storm waves excited in the Baltic Proper. In particular, the joint distribution of wave heights and periods signifies that the role of remote long-period swell is negligible in this area. This peculiarity may simply reflect the low frequency of strong easterly winds in the Baltic Sea basin (Mietus, 1998). Together with the small size of the sea area it allows for a considerable simplification of the reproduction of wave parameters for engineering applications: in a great many cases the wave height, period and direction are determined by the local wind and fetch length.

Although the discussed wave hindcasts ultimately represent all the main features of the wave climate at the Darss Sill, there is still an urgent need for the improvement of the quality of wave models for this area. The presented data vividly express some of the bottlenecks and bring evidence about others. The differences between the simulated and recorded wave climates are not very striking but still important. There are significant differences in the average values, in the frequency distributions, in the extreme values and in the long-term trends of several wave parameters. Most notably, the long-term significant wave height is systematically over-predicted by both hindcasts. On the one hand, this is to some extent unfortunate because the information inferred about the climatic trends obtained with the discussed hindcasts needs additional verification. On the other hand, the systematic quantification of the discrepancies, a by-product of this study of the wave climate, provides important information in order to correctly deal with similar wave climate studies.

Some shortcomings of the modelling efforts may have a straightforward solution. While it is not clear how to correctly handle the systematic over-prediction of the longer wave fields, a proper treatment of shorter components is feasible. The performed analysis reveals that both wave recordings and numerical simulations using a standard range of wave frequencies may substantially deform the distribution of shorter periods, especially in the range $<3 \mathrm{~s}$. In reality, it is natural to expect a considerable fraction of waves with periods of 2-2.5 s in this and similar sea areas (ZaitsevaPärnaste et al., 2009, 2011). This shortage apparently can be removed by increasing the range of frequencies up to $\sim 1 \mathrm{~Hz}$ in order to properly resolve short-wave situations. Such an increase would also make it easier to adequately represent the wave growth curves under low winds and after long-term calm situations (Soomere, 2005; Tuomi et al., 2011). The limitations of the waverider are apparently deeper and some other means such as, acoustical sensors (Didenkulova, 2011) or laser-based devices fixed to offshore platforms, should be used in order to properly resolve the short-wave domain.

In the light of a number of studies that show an increase in the wind speed in the SW Baltic Sea (e.g. Pryor and Barthelmie, 2003) it is remarkable that the analysed data, both measured and hindcast, reveal essentially no changes in the wave heights over the last half-century. This feature demonstrates that wave parameters in semi-sheltered sea areas such as the Baltic Sea depend on the wind parameters in a complicated manner and that they frequently are more strongly affected by (changes in) the wind direction (Soomere and Räämet, 2011b). The reported results support the conjecture that the temporal course in the mean wave height is often decoupled from the course of the mean wind speed (Broman et al., 2006; Räämet and Soomere, 2011b). Finally, it is interesting to mention that the shift in high wind speeds from November-December to January-March (Lehmann et al., 2011) apparently has largely occurred at the turn of the century or even during the latter decade.

Acknowledgements. This study was supported by the Estonian Science Foundation (grant No. 9125), targeted financing by the Estonian Ministry of Education and Research (grant SF0140007s11) and the RADOST project (http://www.klimzug-radost.de/en). The research was partially performed within the framework of the BalticWay project, which is supported by funding from the European Community's Seventh Framework Programme (FP/2007-2013) under grant agreement No. 217246 made with the joint Baltic Sea research and development programme BONUS. TS is deeply grateful to Alexander von Humboldt Foundation for granting the research stay in the HZG in June-September 2011.

Edited by: A. Sterl

\section{References}

Alexandersson, H., Schmith, T., Iden, K., and Tuomenvirta, H.: Long-term variations of the storm climate over NW Europe, Global Atm. Ocean System, 6, 97-120, 1998.

Augustin, J.: Das Seegangsklima der Ostsee zwischen 1958-2002 auf Grundlage numerischer Daten (Sea state climate of the Baltic Sea 1958-2002 based on numerical data), Diploma Thesis, Institute for Coastal Research, GKSS Research Center Geesthacht, Germany, 2005 (in German).

[BACC] The BACC Author Team: Assessment of climate change for the Baltic Sea basin, Reg. Clim. Stud., Springer, Berlin Heidelberg, 474 pp., 2008.

Barstow, F. B., Haug, O., and van der Vlugt, T.: A field validation of a Directional Waveriders in a SEAWATCH buoy, in: Oceans Engineering for Today's Technology and Tomorrow's Preservation (OCEANS 1994), 13-16 Sept. 1994, Brest, France, IEEE, 2, II/32-II/37, doi:10.1109/OCEANS.1994.364011, 1994.

Blomgren, S., Larson, M., and Hanson, H.: Numerical modeling of the wave climate in the southern Baltic Sea, J. Coast. Res., 17, 342-352, 2001. 
Broman, B., Hammarklint, T., Rannat, K., Soomere, T., and Valdmann, A.: Trends and extremes of wave fields in the northeastern part of the Baltic Proper, Oceanologia, 48, 165-184, 2006.

Bumke, K. and Hasse, L.: An analysis scheme for determination of true surface winds at sea from ship synoptic wind and pressure observations, Bound.-Lay. Meteorol., 47, 295-308, 1989.

Cieślikiewicz, W. and Herman, A.: Wave forecasting over the Baltic Sea and the Gulf of Gdañsk using WAM and SWAN models with wind forcing data modelled by ICM, in: Research works based on the ICM's UMPL Numerical Weather Prediction System results, Wydawnictwa Uniwersytetu Warszawskiego, 97108, 2002.

Cieślikiewicz, W. and Papliñska-Swerpel, B.: A 44-year hindcast of wind wave fields over the Baltic Sea, Coast. Eng., 55, 894-905, 2008.

Didenkulova, I.: Shapes of freak waves in the coastal zone of the Baltic Sea (Tallinn Bay), Boreal Environ. Res., 16, 138-148, 2011.

Feser, F., Weisse, R., and von Storch., H.: Multi-decadal atmospheric modeling for Europe yields multi-purpose data, Eos Transactions, 82, 305-310, 2001.

Gayer, G., Günther, H., and Winkel, N.: Wave climatology and extreme value analysis for the Baltic Sea area off the Warnemünde harbour entrance, Deutsche Hydrogr. Zeitschr., 47, 109-130, 1995.

Jaagus, J. and Kull, A.: Changes in surface wind directions in Estonia during 1966-2008 and their relationships with large-scale atmospheric circulation, Estonian J. Earth Sci., 60, 220-231, 2011.

Jönsson, A., Broman, B., and Rahm, L.: Variations in the Baltic Sea wave fields, Ocean Eng., 30, 107-126, 2003.

Kahma, K., Pettersson, H., and Tuomi, L.: Scatter diagram wave statistics from the northern Baltic Sea, MERI - Report Series of the Finnish Institute of Marine Research, 49, 15-32, 2003.

Kalnay, E., Kanamitsu, M., Kistler, R., Collins, W., Deaven, D., Gandin, L., Iredell, M., Saha, S., White, G., Woollen, J., Zhu, Y., Chelliah, M., Ebisuzaki, W., Higgins, W., Janowiak, J., Mo, K., Ropelewski, C., Wang, J., Leetmaa, A., Reynolds, R., Jenne, R., and Joseph, D.: The NCEP/NCAR reanalysis project, Bull. Am. Meteorol. Soc., 77, 437-471, 1996.

Kelpšaitè, L., Herrmann, H., and Soomere, T.: Wave regime differences along the eastern coast of the Baltic Proper, Proc. Estonian Acad. Sci., 57, 225-231, 2008.

Kelpšaitè, L., Dailidienè, I., and Soomere, T.: Changes in wave dynamics at the southeastern coast of the Baltic Proper during 1993-2008, Boreal Environ. Res., 16, 220-232, 2011.

Kistler, R., Kalnay, E., Collins, W., Saha, S., White, G., Wollen, J., Chelliah, M., Ebisuzaki, W., Kanamitsu, M., Kousky, V., van den Dool, H., Jenne, R., and Fioriono, M.: The NCEP/NCAR 50year reanalysis: monthly means CD-ROM and documentation, Bull. Am. Meteorol. Soc., 82, 247-267, 2001.

Komen, G. J., Cavaleri, L., Donelan, M., Hasselmann, K., Hasselmann, S., and Janssen, P. A. E. M.: Dynamics and modelling of ocean waves, Cambridge University Press, 532 pp., 1994.

Lehmann, A., Getzlaff, K., and Harlass, J.: Detailed assessment of climate variability in the Baltic Sea area for the period 1958 to 2009, Clim. Res., 46, 185-196, 2011.

Lopatukhin, L. I., Bukhanovsky, A. V., Ivanov, S. V., and Tshernyshova, E. S.: Handbook of wind and wave regimes in the Baltic Sea, North Sea, Black Sea, Azov Sea and the Mediter- ranean, Russian Shipping Registry, St. Petersburg, 450 pp., 2006 (in Russian).

Marrtensson, N. and Bergdahl, L.: On the wave climate of the southern Baltic, Report Series A:15, Department of Hydraulics, Chalmers University of Technology, Göteborg, 1987.

Mietus, M.: The climate of the Baltic Sea Basin, Marine meteorology and related oceanographic activities, Report No. 41, World Meteorological Organisation, Geneva, 64 pp., 1998.

Mietus, M. and von Storch, H.: Reconstruction of the wave climate in the Proper Baltic Basin, April 1947-March 1988, GKSS Report 97/E/28, Geesthacht, 1997.

Myrberg, K., Ryabchenko, V., Isaev, A., Vankevich, R., Andrejev, O., Bendtsen, J., Erichsen, A., Funkquist, L., Inkala, A., Neelov, I., Rasmus, K., Rodriguez Medina, M., Raudsepp, U., Passenko, J., Söderkvist, J., Sokolov, A., Kuosa, H., Anderson, T. R., Lehmann, A., and Skogen, M. D.: Validation of threedimensional hydrodynamic models in the Gulf of Finland based on a statistical analysis of a six-model ensemble, Boreal Environ. Res., 15, 453-479, 2010.

Papliñska, B.: Wave analysis at Lubiatowo and in the Pomeranian Bay based on measurements from 1997/1998 - comparison with modelled data (WAM4 model), Oceanologia, 41, 241-254, 1999.

Papliñska, B.: Specific features of sea waves in the Pomeranian Bay, Arch. Hydro-Eng. Envir. Mech., 48, 55-72, 2001.

Pettersson, H., Lindow, H., and Schrader, D.: Wave climate in the Baltic Sea 2009. HELCOM Indicator Fact Sheets, 2010, http:// www.helcom.fi/environment2/ifs/en_GB/cover/, last accessed: 6 February 2012, 2010.

Pryor, S. C. and Barthelmie, R. J.: Long-term trends in near-surface flow over the Baltic, Int. J. Climatol., 23, 271-289, 2003.

Pryor, S. C., Barthelmie, R. J., and Schoof, J. T.: The impact of nonstationarities in the climate system on the definition of 'a normal wind year': a case study from the Baltic, Int. J. Climatol., 25, 735-752, 2005.

Räämet, A. and Soomere, T.: The wave climate and its seasonal variability in the northeastern Baltic Sea, Estonian J. Earth Sci., 59, 100-113, 2010.

Räämet, A., Suursaar, Ü., Kullas, T., and Soomere, T.: Reconsidering uncertainties of wave conditions in the coastal areas of the northern Baltic Sea, J. Coast. Res., Special Issue 56, 257-261, 2009.

Räämet, A., Soomere, T., and Zaitseva-Pärnaste, I.: Variations in extreme wave heights and wave directions in the northeastern Baltic Sea, Proc. Estonian Acad. Sci., 59, 182-192, 2010.

Ryabchuk, D., Leont'yev, I., Sergeev, A., Nesterova, E., Sukhacheva, L., and Zhamoida, V.: Morphology of sand spits and the genesis of longshore sand waves on the coast of the eastern Gulf of Finland, Baltica, 24, 13-24, 2011.

Rzheplinsky, G. V.: Wave and wind atlas for the Baltic Sea. Head Office of the Hydrometeorological Services at the Council of Ministers of the USSR, Tallinn, 1965 (in Russian).

Schmager, G., Fröhle, P., Schrader, D., Weisse, R., and MüllerNavarra, S.: Sea state, tides, in: State and Evolution of the Baltic Sea 1952-2005, edited by: Feistel, R., Nausch, G., and Wasmund, N., Wiley, Hoboken, New Jersey, 143-198, 2008.

Soomere, T.: Wind wave statistics in Tallinn Bay, Boreal Environ. Res., 10, 103-118, 2005.

Soomere, T.: Extremes and decadal variations of the northern Baltic Sea wave conditions, in: Extreme Ocean Waves, edited by: Peli- 
novsky, E. and Kharif, Ch., Springer, 139-157, 2008.

Soomere, T. and Kurkina O.: Statistics of extreme wave conditions in the southwestern Baltic Sea, Fund. Appl. Hydrophys., 4(4), 43-57, 2001 (in Russian).

Soomere, T. and Räämet, A.: Long-term spatial variations in the Baltic Sea wave fields, Ocean Sci., 7, 141-150, doi:10.5194/os7-141-2011, 2011a.

Soomere, T. and Räämet, A.: Spatial patterns of the wave climate in the Baltic Proper and the Gulf of Finland, Oceanologia, 53, 335-371, 2011b.

Soomere, T., Behrens, A., Tuomi, L., and Nielsen, J. W.: Wave conditions in the Baltic Proper and in the Gulf of Finland during windstorm Gudrun, Nat. Hazards Earth Syst. Sci., 8, 37-46, doi:10.5194/nhess-8-37-2008, 2008.

Soomere, T., Zaitseva-Pärnaste, I., and Räämet, A.: Variations in wave conditions in Estonian coastal waters from weekly to decadal scales, Boreal Environ. Res., 16, 175-190, 2011.

Sterl, A. and Caires, S.: Climatology, variability and extrema of ocean waves - the web-based KNMI/ERA-40 wave atlas, Int. J. Climatol., 25, 963-977, 2005.

Tuomi, L., Kahma, K. K., and Pettersson, H.: Wave hindcast statistics in the seasonally ice-covered Baltic Sea, Boreal Environ. Res. 16, 451-472, 2011.

Vethamony, P., Aboobacker, V. M., Menon, H. B., Kumar, K. A., and Cavaleri, L.: Superimposition of wind seas on pre-existing swells off Goa coast, J. Mar. Syst., 87, 47-54, 2011.
WASA Group: The WASA project: changing storm and wave climate in the northeast Atlantic and adjacent seas? in: Proc. Fourth International Workshop on Wave Hindcasting and Forecasting, Banff, Canada, October 16-20, 31-44; also: GKSS Report 96/E/61, 1995.

WASA Group: Changing waves and storms in the northeast Atlantic, Bull. Am. Meteorol. Soc., 79, 741-760, 1998.

Weisse, R. and Günther, H.: Wave climate and long-term changes for the southern North Sea obtained from a high-resolution hindcast 1958-2002, Ocean Dyn., 57, 161-172, 2007.

Weisse, R. and von Storch H.: Marine climate and climate change. Storms, wind waves and storm surges, Springer, Berlin, Heidelberg, 220 pp., 2010.

Weisse, R., von Storch, H., Callies, U., Chrastansky, A., Feser, F., Grabemann, I., Günther, H., Pluess, A., Stoye, T., Tellkamp, J., Winterfeldt, J., and Woth, K.: Regional meteorological marine reanalyses and climate change projections: results for Northern Europe and potential for coastal and offshore applications, Bull. Am. Meteorol. Soc., 90, 849-860, 2009.

Zaitseva-Pärnaste, I., Suursaar, Ü., Kullas, T., Lapimaa, S., and Soomere, T.: Seasonal and long-term variations of wave conditions in the northern Baltic Sea, J. Coast. Res., Special Issue 56, 277-281, 2009.

Zaitseva-Pärnaste, I., Soomere, T., and Tribštok, O.: Spatial variations in the wave climate change in the eastern part of the Baltic Sea, J. Coast. Res., Special Issue 64, 195-199, 2011. 